\title{
Researchon Consideration Enhancement System Utilizing Virtual Reality and EEG Biofeedback
}

\author{
R. Vasuki, R. Kishore Kanna,T.Manoj Prasath, S. Geetha
}

\begin{abstract}
The ongoing increment in PC utilization in prescription and recovery has changed the manner in which medicinal services is conveyed. Computer generated Reality innovation gives explicit boosts that can be utilized in evacuating diversions and giving situations that stand out enough to be noticed and expanding their capacity to think. What's more, Virtual Reality innovation can hold a patient's consideration for a more extended timeframe than different strategies can, in light of the fact that $V R$ is vivid, intelligent and imaginal.

In light of these perspectives, we created Attention Enhancement System (AES) utilizing Virtual Reality innovation and EEG biofeedback for evaluating furthermore, regarding ADHD youngsters just as expanding the capacity to focus of kids who have consideration trouble.
\end{abstract}

\section{INTRODUCTION}

That is Interest. Controlling some virtual items, conversing with symbols, and strolling through the virtual space, individuals check out the Virtual Environment (VE). This isn't bound to just learners of VR. Intrigue is one of the real preferences of VR and it is the wellspring of making another innovation. Thusly, we can characterize VR as a coordinated group of four of "Drenching InteractionImagination-Interest".

As of late, expanded PC use in Medicine and Rehabilitation has changed the manner in which social insurance is conveyed. Virtual medical procedure, VR life structures mentor, On-line quiet databases, pre-medical procedure recreation, computerized radiography, master frameworks, and remote discussion is permitted today with the intensity of PCs [4]. What's more, Virtual Reality Therapy (VRT) is an imaginative worldview of VR in Medicine [5].

\section{Virtual RealityTherapy}

Psychological Behaviour Therapists trust that insight mediates one's feelings and conduct. They additionally trust that confidence or figured related with irregular conduct can be observed and changed. In conclusion, in the event that they change one's perception, his or her conduct and feeling must be changed supportable [6].

In treating mental turmoil, existing Cognitive-Behaviour treatment has some powerless focuses. Introduction treatment as Cognitive-Behaviour treatment gives patients a few improvements that reason nervousness or dread. Be that as it may, much late research shows cap various patients

Revised Manuscript Received on August 19, 2019.

Dr. R. Vasuki,Department of Biomedical Engineering, Biher.

R.KishoreKanna,Department of Biomedical Engineering, Biher. (kishorekanna007@gmail.com)

T.ManojPrasath,Department of Biomedical Engineering, Biher.

S.Geetha, Department of Biomedical Engineering, Biher. have issues with envisioning the horrendous scenes and here and there presentation to genuine circumstances is perilous for them [7,8]Additionally, VRT ensures patient's protection and is increasingly affordable contrasted and genuine presentation treatment.

In the most recent decade, numerous sorts of VRT frameworks (for Acrophobia, Agoraphobia, Fear of flight, Fear of open talking, etc) have been created and are clinically demonstrated for their efficacy as CognitiveBehavior therapy $[9,10,11,12,13,14]$.

\section{Attention Deficit Hyperactivity Disorder (ADHD)}

Consideration should be the data the board procedure in which seriousness, supportability, particularity and controllability consolidate and connect. To clarify consideration deficiency, the consideration procedure is commonly partitioned into five segments: centered consideration, supported consideration, particular consideration, rotating consideration and isolated consideration

ADHD is the most regularly analyzed youth conduct issue. Kids who are determined to have ADHD for the most part experience difficulty in focusing, are effectively diverted, imprudent, and hyperactive. As it were, they just can't keep still or to concentrate on the job needing to be done.

Rizzo proposed the Virtual Classroom for the evaluation and recovery of consideration shortages. This investigation demonstrates that VR can be utilized in the appraisal of consideration just as psychological preparing and can offer better prescient data with respect to execution in the genuine condition [22].

\section{ADHD Treatment as Cognitive-Behavior Therapy}

For conquering the breaking points of psycho stimulant prescription, another way to deal with oversee ADHD has been the utilization of social treatment. Since the mid-1970s, various investigations have been led to assess the adequacy of conduct adjustment and treatment for kids with ADHD.

Social mediations impact present moment improvement of ADHD manifestations and these impacts are practically identical in certain perspectives to those got with low dosages of stimulant drug. In any case, social alteration procedures are confused and tedious, and absence of consistency and finish can decrease the viability of the mediation.

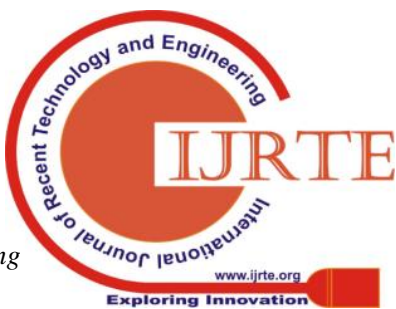


Past investigations of EEG have given some illumination in the components hidden ADHD. Furthermore, EEG biofeedback treatment result considers for ADHD have revealed promising outcomes not just in critical decreases in hyperactive, unmindful, and problematic practices, yet in addition enhancements in scholarly execution and IQ scores $[24,25]$. As of late, Othmer and Kaiser proposed the utilization of EEG Biofeedback, or Neuro feedback, with Virtual Reality [26].

A few research thinks about have appeared Virtual Reality innovation gives explicit boosts that can be utilized in evacuating diversions and giving conditions that stand out enough to be noticed and builds their fixation [5,22]. The experience of quality in a VE requires specific consideration [27]. That is, encountering nearness in remote activities task or in a VE requires the capacity to concentrate on one genuinely reasonable arrangement of upgrades to the prohibition of disconnected improvements.

What's more, Virtual Reality innovation can hold a patient's consideration for a more drawn out timeframe than different strategies can, on the grounds that VR is vivid, intelligent and imaginal. Or more all, it is intriguing. Thinking about these viewpoints, we created Attention Enhancement System (AES) utilizing Virtual Reality innovation and EEG biofeedback for evaluating and regarding ADHD kids just as improving kids' consideration who have consideration trouble (not ADHD).

\section{ATTENTION ENHANCEMENT SYSTEM}

\section{The Virtual Environment - AClassroom}

Since the kids and young people invest much energy in their study hall, they ought to be mindful to the study hall errands. In this way, as our first venture, we built up the study hall based virtual situations for closeness and concentrated consideration improvement.

\section{Virtual Reality CognitiveTraining.}

\section{Computer generated Reality Cognitive Training}

The virtual study hall is personal and vivid for kids, so they effectively focus on the study hall condition itself. In any case, the preparation assignments of our framework are not all that intriguing to them. We created two subjective instructional classes: Virtual Reality Comparison Training and Virtual Reality Sustained Attention Training.

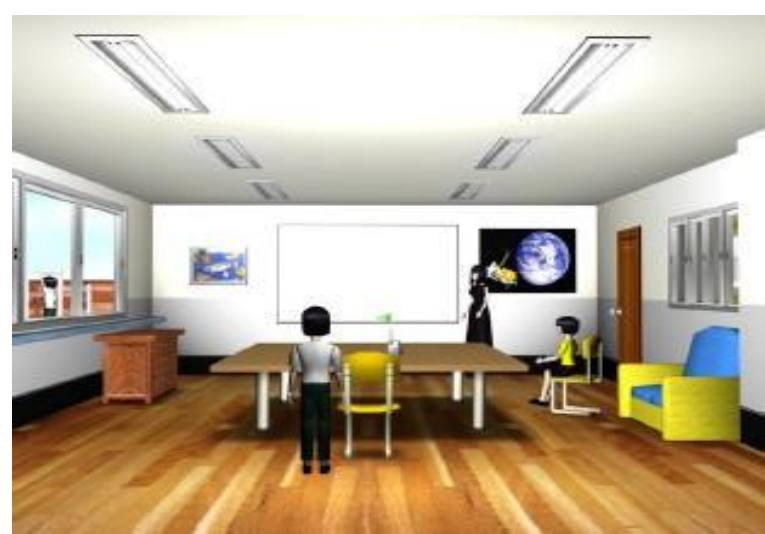

Figure 1.Application virtual condition of a study hall
Computer generated Reality Comparison Training (VRCT) is for upgrading concentrated and specific consideration of a subject. At the point when the instructional meeting begins, a subject can see two three dimensional items on the work area. For instance, a circle and a square column. Those items are here and there indistinguishable and at times extraordinary. On the off chance that indistinguishable items are introduced, one of those is once in a while yawed, pitched or rolled marginally. Along these lines subjects should focus on that. In the event that a subject chooses those are same, the individual in question is urged to press the left mouse catch. Else, the person must press the correct catch. For every session, a subject rehashes this standard multiple times.

We can quantify the quantity of right answers and the reaction times. On the off chance that the quantity of right answers is more than 57 , a subject will go to the following stage in the accompanying session. As the subject advances through the stages, the timeframe the person can see the items diminishes progressively and the articles gave objects are less discernable: for instance, a triangular pyramid and a quadrangular pyramid. There are 10 organizes altogether. Figure 2 demonstrates a case of this preparation.

Figure 2 . An example view of VRCT

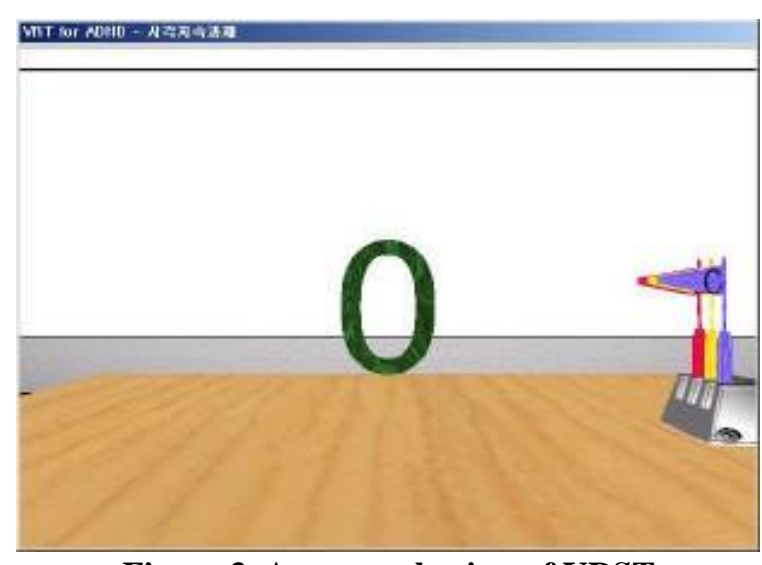

Figure 3. An example view of VRST

The stage-finishing strategy is equivalent to the one in VRCT. In any case, not at all like VRCT, as the subject advances to larger amount arranges, the timeframe that the upgrades (numerals) are exhibited increments bit by bit. Thus the subject ought to have significantly more perseverance and needs to focus on the undertaking ceaselessly. In this instructional class, we additionally measure the quantity of right answers and reaction times, much the same as in VRCT. There are additionally 10 arranges in VRST. 


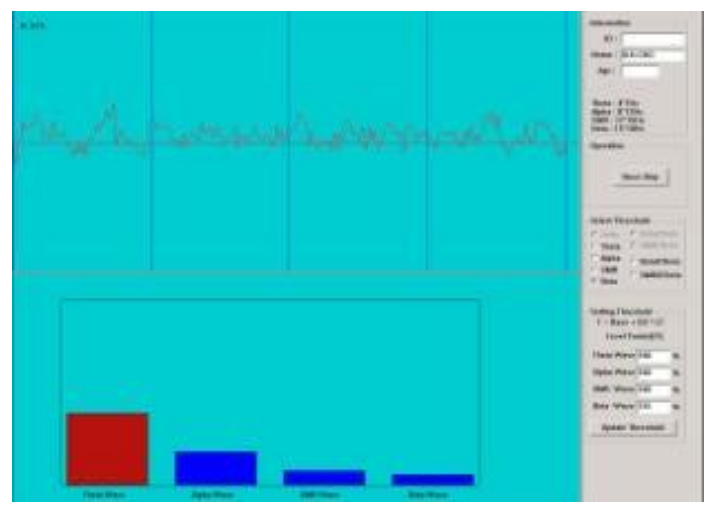

Figure 4. Operator's view of EEG Biofeedback Analysis Module

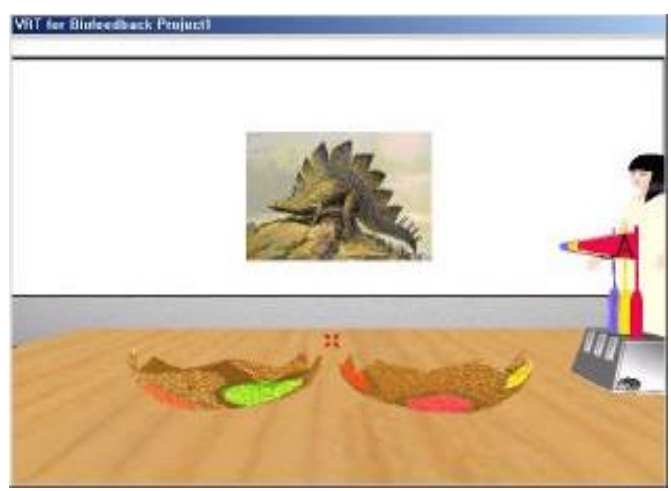

Figure 5. An example of EEG Biofeedback training : a completed scene

\section{EXPERIMENTS RESULTS}

50 subjects, matured 14 to 18 , who had carried out wrongdoings and had been segregated in a reformatory, participated in this investigation. They had some trouble in learning in school and they were absentminded, hasty, hyperactive and occupied. In spite of the fact that they were not formally analyzed as ADHD, about $30 \%$ of them in all likelihood had ADHD.

They were arbitrarily allocated to one of five 10-subject gatherings: a control Group, two fake treatment gatherings, and two exploratory gatherings. Each gathering comprised of 10 subjects, separately (Table 2). The test gatherings and the fake treatment bunches experienced 8 sessions more than about fourteen days, which were around 20 minutes long. The control bunch experienced no instructional meeting amid a similar timeframe.

Our hypothesis is that Virtual Reality is valuable for thought. In addition, we moreover place that VR-EEG Biofeedback getting ready and our mental instructional classes in like manner supports thought improvement. That is the reason we isolated the subjects into five social occasions.

\begin{tabular}{|l|l|l|}
\hline Group & Training task & $\begin{array}{l}\text { Number } \\
\text { ofsubjects }\end{array}$ \\
\hline $\begin{array}{l}\text { Control } \\
\text { Group }\end{array}$ & Waiting & 10 \\
\hline $\begin{array}{l}\text { Placebo Group } \\
1\end{array}$ & $\begin{array}{l}\text { Desk-Top VR EEG } \\
\text { Biofeedback Training } \\
\text { (DVRBT) }\end{array}$ & 10 \\
\hline
\end{tabular}

\begin{tabular}{|l|l|l|}
\hline $\begin{array}{l}\text { Placebo } \\
\text { Group2 }\end{array}$ & $\begin{array}{l}\text { Desk-Top VR } \\
\text { Cognitive } \\
\text { Training (DVRCT) }\end{array}$ & 10 \\
\hline $\begin{array}{l}\text { Experimental } \\
\text { Group 1 }\end{array}$ & $\begin{array}{l}\text { Virtual Reality EEG } \\
\text { Biofeedback Training } \\
\text { (VRBT) }\end{array}$ & 10 \\
\hline $\begin{array}{l}\text { Experimental } \\
\text { Group 2 }\end{array}$ & $\begin{array}{l}\text { Virtual Reality } \\
\text { Cognitive } \\
\text { Training (VRCT) }\end{array}$ & 10 \\
\hline
\end{tabular}

Table 2. Training groups

Results:

Mean pre-and post-preparing CPT scores and the standard deviation of each score are introduced in Table 3. The rehashed measure MANOVA test was utilized to assess the impact of AES.

\begin{tabular}{|c|c|c|c|c|c|}
\hline & Ex. 1 & Ex. 2 & Pl. 1 & Pl. 2 & Con. \\
\hline \multicolumn{6}{|c|}{ The number of correct answers } \\
\hline Pre & $\begin{array}{c}310.38(6.93 \\
)\end{array}$ & $\begin{array}{c}310.78(5 . \\
02)\end{array}$ & $\begin{array}{c}312.00(6 . \\
14)\end{array}$ & $\begin{array}{c}312.50(5.2 \\
8)\end{array}$ & $\begin{array}{c}314.78(5.4 \\
7)\end{array}$ \\
\hline Post & $\begin{array}{c}319.75(2.92 \\
)\end{array}$ & $\begin{array}{c}320.44(2 . \\
60)\end{array}$ & $\begin{array}{c}316.44(2 . \\
83)\end{array}$ & $\begin{array}{c}316.90(5.5 \\
9)\end{array}$ & $\begin{array}{c}315.44(4.4 \\
5)\end{array}$ \\
\hline \multicolumn{6}{|c|}{ The number of omission errors } \\
\hline Pre & $\begin{array}{c}13.63(6.93 \\
)\end{array}$ & $\begin{array}{c}13.22(5.02 \\
)\end{array}$ & $\begin{array}{c}12.00(6.1 \\
4)\end{array}$ & $\begin{array}{c}10.50(5.87 \\
)\end{array}$ & $9.22(5.47)$ \\
\hline Post & $4.25(2.92)$ & $3.67(2.60)$ & $\begin{array}{c}7.56(2.83 \\
)\end{array}$ & $7.10(5.59)$ & $8.56(4.45)$ \\
\hline \multicolumn{6}{|c|}{ The number of commission errors } \\
\hline Pre & 23.13(4.91) & $\begin{array}{c}19.44(7.6 \\
7)\end{array}$ & $\begin{array}{c}19.11(7.1 \\
7)\end{array}$ & $\begin{array}{c}17.10(9.97 \\
)\end{array}$ & $\begin{array}{c}19.11(7.77 \\
)\end{array}$ \\
\hline Post & $17.00(7.65)$ & $\begin{array}{c}12.67(10 \\
33)\end{array}$ & $\begin{array}{c}13.56(5.7 \\
3)\end{array}$ & $\begin{array}{c}16.30(11.1 \\
2)\end{array}$ & $\begin{array}{c}15.11(10.4 \\
7)\end{array}$ \\
\hline \multicolumn{6}{|c|}{ Reaction time ( $\mathrm{T}$ score) } \\
\hline Pre & $\begin{array}{c}48.37(12.3 \\
5)\end{array}$ & $\begin{array}{c}54.52(15.7 \\
2)\end{array}$ & $\begin{array}{c}53.85(13 . \\
96)\end{array}$ & $\begin{array}{c}49.50(14.3 \\
2)\end{array}$ & $\begin{array}{c}52.77(17.8 \\
9)\end{array}$ \\
\hline
\end{tabular}

Table 3. Mean CPT scores of subjects. Ex. implies Experimental gathering, Pl. implies Placebo gathering, and Con. implies Control gathering. Standard deviation of the scores in brackets.

The quantity of right answers, exclusion blunders and reaction affectability ( $\left.d^{\prime}\right)$ for test bunches demonstrates huge improvement $(\mathrm{p}<0.01)$ while control bunch shows no huge change. Thus Inattentiveness of the trial bunches ended up diminished and they should be reliably mindful. The

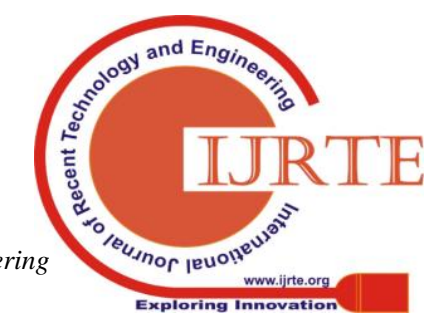


commission blunders and reaction times were additionally diminished to a little degree yet those were not noteworthy.

\begin{tabular}{|l|l|l|l|l|l|}
\hline Post & $\begin{array}{l}40.84(12 \\
.86)\end{array}$ & $\begin{array}{l}38.62(19 . \\
80)\end{array}$ & $\begin{array}{l}47.10(11 . \\
95)\end{array}$ & $\begin{array}{l}48.85(17 \\
.30)\end{array}$ & $\begin{array}{l}47.16( \\
22.88)\end{array}$ \\
\hline \multicolumn{5}{|l|}{} \\
\hline Response sensitivity (Attentiveness, T score) \\
\hline Pre & $57.33(7$. & $55.35(8.3$ & $55.60(6.0$ & $55.62(10$ & 53.33( \\
& $73)$ & $0)$ & $2)$ & $.52)$ & $5.52)$ \\
\hline Post & $49.28(9$. & $41.83(7.7$ & $51.44(4.4$ & $49.77(17$ & 50.52( \\
& $49)$ & $0)$ & $9)$ & $.19)$ & $10.77)$ \\
& & & & & \\
\hline
\end{tabular}

\section{CONCLUSION:}

Vivid VR might be fitting for consideration upgrade. For certain subjects, they said that preparation just with a screen, that is work area VR, was monotonous and awkward. In any case, with a HMD, they were roused instead of exhausted. At that point, VR based EEG Biofeedback preparing is additionally pertinent to that. In a specific perspective, EEG Biofeedback preparing is tedious and troublesome for youngsters and pre-adult.

Anyway it was troublesome for the subjects to comprehend just as total. Despite the fact that we utilized just Beta wave as an input control on EEG Biofeedback, we made noteworthy outcomes. Be that as it may, sooner rather than later, we will utilize another convention, for example, Beta/Theta criticism control, compensate for the feeble purposes of our preparation substance and improve the realistic nature of VR.

\section{REFERENCES:}

1. G. Burdea, and P. Coiffet, Virtual Reality Technology, John Wiley \& Sons, Inc., New York, 1994.

2. J. Vince, Essential Virtual Reality Fast:how to understand thetechniquesandpotentialofvirtualreality,Springer-Verlag., New York, 1998.

3. G. Burdea, "Virtual Reality Systems andApplications,"Electro'93 International Conference, Edison, NJ, 1993, pp. 164.

4. R. Taylor, S. Lavellee, G. Burdea and R. Moesges, Virtual Computer Integrated Surgery, MIT Press., USA,1994.

5. M. North, S. North and J. Coble, Virtual Reality Therapy: An Innovative Paradigm, IPI Press, Colorado Springs, 1996.

6. H. Won, S. et al., Cognitive-Behavioral Approach to mental disorder, Education \&Science Inc., Korea,2000.

7. R. Bloom, Psychiatric Therapeutic Applications of Virtual Reality Technology (VRT): Research Prospectus and Phenomenological Critique, Medicine Meets Virtual Realty IOS Press, 1997

8. D. Strickland, L. Hodges, M. North and S. Weghorst, "Overcoming Phobias by Virtual Exposure", Comm. ACM, Vol. 40, No. 8, 1997, pp.34-39.

9. B. Rothbaum, L. Hodges, R. Kooper, D. Opdyke, J. Willford and M. North, "Effectiveness of Computer-Generated (Virtual Reality) Graded Exposure in the Treatment of Acrophobia", Am J Psychiatry 154:4, 1995, pp. 626-628

10. M. North, S. North and J. Coble, "Virtual Environments Psychotherapy:ACaseStudyofFearofFlyingDisorder",Presence , Vol. 6, No. 1, Feb. 1997, pp. 127-132

11. M. North, S. North and J. Coble, "Effectiveness of Virtual Environment Desensitization in The Treatment of
Agoraphobia", The International Journal of Virtual Reality, Vol. 1, No. 2, 1995, pp.25-34

12. M. North and S. North, "Relative Effectiveness of Virtual EnvironmentDesensitizationandImaginalDesensitizationinthe Treatment of Aerophobia", The Archnet Electronic Journal on Virtual Culture, Vol. 2, Sep.1994

13. M. Antony, "Assessment and Treatment of SocialPhobia",Can J Psychiatry, Vol. 42, 1997, pp. 826-834

14. M. Slater, D. Paul, Pertaub and A. Steed, "Public Speaking in Virtual Reality: Facing an Audience of Avatars", IEEE ComputerGraphics\&Application,Vol.19,No.2,1999,pp.6-9

15. M. Sohlbert and $\mathrm{C}$. Mateer, Introduction to cognitive rehabilitation: Theory and practice, Guilford, New York, 1989

16. H. Quay and A. Hogan, Handbook of Disruptive Behavior Disorders, Kluwer Academic/Plenum Publishers, New York, 1999

17. M. Maruish and J. Moses, Jr, Clinical Neuropsychology: Theoretifcal Foundations for Practitioners, Lawrence Erlbaum Associates, Inc, New Jersey,1997

18. R. Barkley, Taking Charge of ADHD, The GuilfordPress, New York, 1995

19. American Psychiatric Association, Diagnostic and statistical manual of mental disorders, Wasington, DC,1994

20. P. Szatmari, "The Epidemiology of Attention-Deficit Hyperactivity Disorders", Child and Adolescent Psychiatric Clinics of North America, Vol. 1, Num. 2, 1992, pp.361-372.

21. W. Pelham, S. Sams, "Behavior Modification", Child and Adolescent Psychiatric Clinics of North America, Vol. 1, No. 2, 1992, pp.505-918

22. A. Rizzo et al, "The Virtual Classroom: A Virtual Reality Environment for the Assessment and Rehabilitation of Attention

Deficits",Cyberpsychology\&Behavior,MaryAnnLiebert,Inc.,V ol. 3, Num. 3, 2000, pp.483-499

23. A. Winkler, J. Dixon and J. Parker, "Brain function in problem children and controls: Psychometric, neurological, electroencephalogiccomparisons", American Journal of Psychiatry, 127, 1970, pp.94-105

24. M. Linden, T. Habib and V. Radojevic, "A controlled Study oftheEffectsofEEGBiofeedbackonCognitionand Behaviorof Children with Attention Deficit Disorder and Learning Disabilities", Biofeedback and Self-Regulation, Vol. 21, No. 1, 1996, pp.35-49.

25. V. Monastra et al, "Assessing Attention Deficit HeperactivityDisorderviaQuantitative

Electroencephalography: An Initial ValidationStudy",

26. Neuropsychology, Vol. 13, No. 3, 1999, pp. 424-433S. Othmer, D. Kaiser, "Implementation of Virtual Reality in EEG Biofeedback", Cyberpsychology\& Behavior, Mary Ann Liebert, Inc., Vol. 3, Num. 3, 2000, pp. 415-420.

27. B. Witmer and M. Singer, "Measuring Presence in Virtual Environments: A Presence Questionnaire", Presence, MITPress, Vol. 7, Num. 3, 1998, pp. 225-240 